\title{
Escenas casi familjares en Fantasmas borrachos de Radrigán en la puesta en escena de Francisco Albornoz. 0 un estudio del amor y la soledad con un poco de humor $^{2}$ \\ Marta Contreras Bustamante \\ Universidad de Concepción, Chile \\ E-mail: mcontre@udec.cl
}

A REFLEXION sobreel concepto de escena tiene extensiones diversas y com- plementarias. En el campo de los estudios teatrales este concepto es una herramienta de trabajo eficaz e ineludible. Así, se aplica a la descripción de los textos llamados dramáticos como al trabajo de la puesta o levantamiento de escena hecho por un director teatral en particular.

El concepto de escena como dispositivo de entrada a los materiales de trabajo de disciplinas como la semántica, la política, la sociología, la criminalística, la narratología, etc., tiene una productividad analítica valiosa.

En el campo teatral el director artístico trabaja con el dispositivo dela escena en una práctica por medio de la cual se ponen y reponen los materiales que la constituyen. Así, él vertebra el trabajo de los actores y reinterpreta la escritura del dramaturgo en un proceso de apropiación-creación del espacio escénico.

En mi trabajo como estudiosa del teatro he comprobado que la escena me

\footnotetext{
${ }^{1}$ La puesta en escena de Fantasmas borrachos dirigida por Francisco Albornoz forma parte del proyecto deinvestigación del área de estudios teatrales dela U niversidad deC oncepción. Se realizó la primera reunión del grupo detrabajo en octubre del 2002. El elenco estuvo conformado por Juan Arévalo, Ximena Ramírez, N elson O late, Norma Gómez, Adolfo Albornoz, Grace I saacson, Christian W inter, Viviana Riveros. Los ensayos se realizaron entre diciembre 2002 y marzo del 2003, efectuándose el estreno el día 27 de marzo. La temporada fue del 27 al 30 de marzo en el Teatro Concepción y del 6 al 13 de abril en el teatro del Colegio M édico. Vieron la obra alrededor de 1.000 personas. La coordinación general del proyecto fue de M arta Contreras, la escenografía de Eduardo M eissner, la música de Fernando Saavedra y Gregorio M adinagoitia, la iluminación de Ana M aría Q uiroz.

${ }^{2}$ Este trabajo fuelé́do en Seminario Teatro Chileno y sus Alrededores, realizado los días 1 , 2 y 3 de abril del 2003 en la Universidad deConcepción.
} 
permite analizar un texto a través de lo que he llamado unidades escénicas ${ }^{3}$, que sin ser unidades rígidas, me permiten entrar en el texto reconociendo los intercambios comunicativos (de toda índole) que aglutinan los sentidos diversos del texto instalados tridimensionalmente en la escritura.

La visión de lo tridimensional es la particular forma de leer el teatro que en su extraña forma avisa de su posiblefuturo esplendor en las tablas, en el escenario material.

En la asistencia al proceso de montaje de una obra en particular observamos que el mismo dispositivo le permiteal director cortar el texto en unidades relativamente autónomas, a través de cuya progresiva apropiación va levantándose una obra teatral plena.

La obra teatral plena es la que en estado de madurez después de un proceso de paulatino levantamiento será mostrada al público a partir del día de su estreno.

¿Cuáles son las escenas que he visto constituirse en Fantasmas borrachos de Juan Radrigán en el reposado levantamiento teatral dirigido por Francisco Albornoz? Las he llamado en su conjunto escenas cuasi-familiares para aprisionar en ese nombre una percepción que me parece iluminadora. U so la palabra iluminación en el sentido de aclaración de un sistema de relaciones cuyo trazo conecta un cuerpo teatral rico en sugerencias y resonancias.

Las figuras que se despliegan en las escenas constituyen una especie de familia emparentada por lazos de situación, de contigüidad metonímica. A la vez, cada uno de los miembros de la figura colectiva pertenece a una serie de la cual es su representante aquí y ahora.

Las escenas son cuasi familiares, en tanto que el parentesco es postizo, y en tanto que habitan en una escena cuasi delictiva. La escena familiar es la escena del delito. Algunos crímenes de diversa natural eza han sido cometidos y aunque la cuestión central de la obra no es castigar a los cul pables, una cierta especie de proceso de aclaración de las evidencias va ocurriendo en el camino.

Lo cuasi familiar se refieretambién al hecho de quelas figuras y sus situaciones pueden ser familiares en el sentido de habituales o conocidas, pero debido a los materiales con los que se han levantado, estas figuras se vuelven extrañas, irreales, es decir, artísticas. Los materiales son los cuerpos de los actores, el diseño de la escenografía que interpreta el espacio escénico, los colores, la iluminación, el vestuario, la música.

${ }^{3}$ Vid. Contreras, M arta. Griselda Gambaro. Teatro de la descomposición. Concepción: Ed. Universidad de Concepción, 1994. 
¿C uáles son estas escenas sobre cuyo diseño el autor-director ha levantado la obra? Voy a enumerarlas:

- Un hombre despierta en un lugar que no conoce.

- Un cantinero y su ayudante abren y cierran un bar.

- Un bar es visitado por figuras de la historia de Chile.

- Unos seres beben en el bar y esperan.

- Un condenado se lamenta de su destino.

- U nas figuras se cimbran impotentes.

- D os ex amantes se encuentran.

- Una mujer busca a su amante desaparecido.

- Una mujer deforme establece su figura en la escena.

- Figuras bailan un bolero de espaldas al público.

- Un hombre se niega a reconocer su realidad.

- U na mujer pierde la esperanza de haber sido amada.

Estas escenas que hasta aquí parecen unidades narrativas convencionales, son frases sintéticas que dan nombre a unas composiciones complejas de lugares, desplazamientos, gestos, actitudes, sentimientos, pasiones, intercambios verbales de las figuras.

¿Cómo estas unidades que visualiza el director en el texto se van convirtiendo en teatro, es decir, en un cuerpo artístico deactores, música, luces, vestuario? A través de lo queyo hellamado las estrategias de dirección deFrancisco Albornoz.

El da particular importancia al trabajo con los actores. El cuerpo de actores, el elenco está constituido por profesionales de diferentes generaciones y escuelas. El se dirige a ellos en una primera ocasión señalando la importancia del grupo y el respeto por el trabajo del compañero en la escena. Se establece un objetivo común. A todos ellos les dice: "Vamos a trabajar rápido confiando en R adrigán". Esta exortación pone las bases del trabajo en la materia dramática de Radrigán, cuestión que en el trascurso de los días se va haciendo más patente. La fuerza y precisión de los diálogos, el arraigo popular y la sinceridad del lenguaje van permitiendo que algo muy poderoso se instale sobre la escena.

A través de una serie de indicaciones que se van entregando a lo largo del proceso según sea necesario, se va instalando en el grupo una manera de trabajar en la que los actores se sienten respaldados por la visión que el director tiene de cada escena de la obra y por la visión que tiene del trabajo de cada actor.

Recojo al gunas deestas frases queimplican una determinada forma deinterpretar el trabajo artístico del director: 
No representar, no caracterizar se establece como un principio estético que cambia la tradicion teatral de la identificación por una que consiste en contar una historia.

Para contar una historia el actor debe dejar transparentar la historia, el actor es un vehículo que busca el lugar expresivo en su propio organismo para usarlo al servicio de la historia cuya final idad natural es emocionar.

El actor se relaciona con el personaje a través de la reflexión y encantamiento con la historia. La historia se va dando a través de estados y situaciones. El actor se sube al carro de la rabia, el dolor, la alegría, sin declamar, "sin irse en la poesía", siendo concreto.

El director recomienda a los actores leer el texto desde dentro "no interpretar todavía". Puesto que el proceso debe tener su tiempo propio de maduración sin adelantarse a los hechos. Los hechos que configuran las escenas y que tienen vida propia.

Las escenas de Radrigán son escenas internas, interacciones íntimas y el director da nombre a esos intercambios: agresión, indiferencia, autocompasión, de modo que el actor sepa qué está pasando en cada escena y encuentre esa situación en su propia experiencia, la identifique y sepa a qué atenerse.

Ejemplo: cuando se trabaja la escena $\mathrm{N}$ - 1 se va dibujando el espacio y se va buscando el ritmo de las palabras y de la música. La dirección de la mirada del actor, el diálogo de miradas y palabras se proyectan al espectador y forman la figura del espectáculo. El desglose de la escena corta cada parte del movimiento para su asimilación por el actor: Ramiro despierta a una realidad donde se siente perdido, no sabe donde está. D espués toma conciencia del lugar. Paulatinamente aterriza en su vida. Los otros personajes están tranquilos y ajenos. Estas frases segmentan la unidad de la escena y permiten la entrada del actor y más tarde la del espectador en el mundo de Ramiro.

"Conversar con el otro, que el diálogo llegue al otro". Esta frase insiste en la verdad de la comunicación, no en el realismo como imitación de la comunicación sino que en lo que tiene que ocurir en la escena entre los actores. M irarse, estar disponiblea la mirada del otro, dirigir las palabras al otro, acusar recibo de esas palabras. Tanto en lo explícito como en lo implícito. La escucha profunda del actor lo pone en el estado requerido para que la escena se llene de vida, de historias de vidas.

"Pensar en voz alta, divagar, buscar". El personajeno está disponible desdeel principio como una unidad sicológica o aun física. Es en la espera meditativa apoyada en las palabras de la escena dialógica de Radrigán que empieza a aparecer, a levantarse con su historia, sus esperanzas, sus mentiras, sus miedos. Es en este proceso que tiene pleno sentido "retardar el proceso de fijación del texto".

Esta atención al trabajo teatral está instalada en una reflexión crítica sobre la 
natural eza de la construcción artística. Y ésta a su vez intenta establecer alguna relación razonable con al gunas tareas pendientes de lo que yo llamo el proyecto educativo nacional. En este proyecto estamos implicados una serie de agentes de los más diversos orígenes. La práctica artística teatral podría ayudarnos a comprender mejor 0 a plantear con mayor claridad esas tareas pendientes que propongo formulemos así.

Cuando se hace un proyecto de montaje se establece una tierra común de trabajo que orienta todas las energías en la misma dirección. Eso es garantía de llevar al proceso a su fin. Es decir, que el grupo trabaja por un objetivo común, cual es al levantamiento de una obra teatral, su establecimiento en el mundo tridimensional y su ofrecimiento a la ciudad en la forma de espectáculo.

En el proceso de ocurrir esta instalación se hacen visibles las condiciones de producción, las vías de comunicación, de todo un sistema de relaciones orgánicas que entran en funcionamiento y exhiben su idiosincrasia, convirtiéndose en un lugar privilegiado de lectura de los modos de funcionamiento institucional y civil de la ciudad artística y letrada.

Creo advertir algunas señas del futuro en este trabajo realizado que tienen que ver con dos asuntos: U no el de las dependencias y los apegos y otro el del ejercicio democrático. Estos son temas que yo llamo tareas pendientes.

Si se propone una escena como esta de R adrigán se está haciendo una operación de sentido por medio de la cual queda en evidencia, ante los ojos, una pérdida irremediable que no termina de desprenderse de la retina y por la cual los sujetos afectados han quedado convertidos en fantasmas persistentes de su añoranza o recurrentes en su error. Pura melancolía rezuman estas escenas que aparentemente no contienen ninguna proposición que salve la situación y nos entregue, por así decirlo, una esperanza de salvación.

Sin embargo, en la paciente y demorada construcción de este mundo teatral, al go se ha ido gestando que merece nuestra más seria consideración. Un grupo de personas de muy diferente edad y escuela se encuentran y se ponen de acuerdo sobre un trabajo de producción teatral. Un director, Francisco Albornoz, tiene una visión de qué hacer y cómo hacerlo con esas personas específicas que se han reunido; además hay una especie de conocimiento del mundo que se va generando a través del apropiarse de los diálogos de Radrigán, por lo cual empieza a surgir una realidad que brilla con fulgor propio.

Este fulgor propio es el que relumbra fugazmente en cada ocasión en la que se abre el telón y el público se emociona, ríe o aplaude en contacto con esa iluminación precisa eintencionada del arte teatral que está en juego en la puesta en escena.

La puesta en escena es metáfora viviente y transitoria de la vida humana, en la que el sentido de lo que se levanta se sostiene, momentáneamente, amarrado 
a una lengua, a un ejército, a una moneda, a un tesoro, a una nueva arma de exterminio, a un tratado de libre comercio, etc.

Se abre el telón y nos asomamos a unas escenas que han sido preparadas intencionalmente y en las que cada elemento está anticipado o producido de acuerdo a ciertas visiones artísticas de los que las ejecutan. En el proceso de ocurrir esto, al guien se despegó de sus fantasmas y los puso a disposición de la audiencia; alguien abandonó su identidad civil y puso su cuerpo a disposición dela obra; al guien se prestó para acarrear utilería, iluminar, vestir los cuerpos de la escena.

En fin, una serie de dependencias e identificaciones fueron puestas en suspensión para que este hecho ocurriera. M ás adelante toda esa construcción es abandonada y el escenario queda vacío. Esta ocurrencia, como lo he dicho antes, ejemplifica una manera de dejar, deabandonar una cierta identificación, de abandonar la escena, esa escena. Esto implica, me parece, un modelo de acción que contradice nuestros hábitos diarios de identidad, de apropiación vitalicia, de instalación sedentaria en los lugares, lo que dicho, de otra manera, corresponde a dejar ocurrir la experiencia de la muerte a través del trabajo preparatorio de sucesivas y pequeñas muertes parciales.

En ese trabajo preparatorio la risa es el síntoma de la sabiduría distanciada que acepta la ineluctable modal idad de nuestra vida, es decir de nuestra muerte.

El trabajo artístico, el trabajo teatral no anticipa la muerte, no arrebata bruscamente la vida, sino que la pone delante por medio de un acto constructivo que suspende su ocurrencia, demorándose en la plenitud de las formas del vivir. Todos los sentidos se afinan, se suspenden los juicios, se sale del ajetreo real para entrar en una experiencia lúdica posiblemente placentera.

D urante los ensayos el director entra en las escenas. Se pone en el lugar del actor, recorreel cuerpo-texto del actor para sugerirle un desplazamiento. En ese recorrido intenta ejemplificar el principio de "el movimiento es pensamiento". Las proyecciones de esta idea son diversas.

Se genera una forma de trabajo democrática. El poder del director no está fuera de las escenas. El director se pone en el lugar del otro y desde ese interior dirige la puesta con el cuerpo del otro. 